\title{
Afirmar a comunicação humanizadora na perspectiva da Teologia Pública
}

\section{Affirm humanizing communication in the perspective of Public Theology}

\section{Afirmar la comunicación humanizadora en la perspectiva de la Teología Pública}

Magali do Nascimento Cunha*

\begin{abstract}
RESUMO
Este texto tem por objetivo abordar a dimensão humanizadora da comunicação sob a perspectiva da Teologia Pública. Com base na metodologia latino-americana "ver, julgar e agir", o estudo apresenta uma síntese da noção de "cultura da convergência" do mundo globalizado. Em um segundo momento, o artigo toma por base a teologia da comunicação, em um diálogo com a teologia bíblica do Gênesis, como parâmetros que desafiam este modo de vida do tempo presente. Na ótica do "agir", o estudo relaciona o que foi abordado com os desafios para uma fé em perspectiva pública. Com base em referencial dos estudos de Comunicação, da Teologia Bíblica e da Teologia Pública, a sistematização bibliográfica compõe a trajetória metodológica do artigo que se propõe uma contribuição aos estudos que relacionam Comunicação e Teologia.
\end{abstract}

Palavras-chave: Comunicação; teologia pública; ver, julgar e agir; cultura da convergência; fé pública.

\begin{abstract}
This text aims at addressing the humanizing dimension of communication on the perspective of Public Theology. Based on the Latin-American methodology "see, judge and act", the study presents a synthesis of the notion of the "culture of convergence" of the globalized world. In a second moment, the article takes as a basis the theology of communication, in a dialogue with the biblical theology of Genesis, as parameters that challenge this way of life of present time. From the viewpoint of the "acting", the study relates what was approached with the challenges for faith in a public perspective. Based on the studies on Communication, Biblical Theology and Public Theology, a bibliographic systematization makes up the methodological trajectory of the article, that intends to be a contribution to the studies that relate Communication and Theology.

Key words: Communication; public theology; see, judge and act; culture of convergence; public faith.

\section{RESUMEN}

Este texto tiene por objetivo abordar la dimensión humanizadora de la comunicación bajo la perspectiva de la Teología Pública. Con base en la metodología latinoamericana "ver, juzgar y actuar", el estudio presenta una síntesis de la noción de "cultura de la convergencia" del mundo globalizado. En un segundo momento, el artículo se basa en la teología de la comu-
\end{abstract}

* Doutora em Ciências da Comunicação com Estágio Pós-Doutoral em Comunicação e Política, pesquisadora em Comunicação e Religião da INTERCOM. 
nicación, en un diálogo con la teología bíblica del Génesis, como parámetros que desafían este modo de vida del tiempo presente. En la óptica del “actuar", el estudio relaciona lo que se abordó con los desafíos para una fe en perspectiva pública. Con base em el referencial de los estudios de Comunicación, de la Teología Bíblica y de la Teología Pública, la sistematización bibliográfica compone la trayectoria metodológica del artículo que se propone una contribución a los estudios que relacionan Comunicación y Teología.

Palabras clave: Communicación; teología pública; ver, juzgar y actuar; cultura de la convergência; fé pública.

A base para esta reflexão sobre a comunicação humana como uma importante dimensão de diálogo com a Teologia Pública é a metodologia latino-americana "Ver, julgar e agir". Quando "vemos" o que está diante de nós, que estamos imersos na chamada "cultura da convergência" no Mundo Global, refletimos sobre a cultura que possibilita transformações no modo de ser e viver em todas as partes do mundo, e que traz mudanças significativas para a comunicação humana. A esta reflexão se dedica a primeira parte deste artigo. A segunda parte apresenta o "julgar", abordando os aspectos críticos relacionados à midiatização das relações humanas, sentido que revela um retrato da contemporaneidade, através da teologia latino-americana. A última parte do artigo, o "Agir", aponta para possibilidades de ações concretas para a humanização dos processos de comunicação em diálogo com as bases da Teologia Pública.

A reflexão teológica que ajuda a "julgar" baseia-se na teologia da comunicação, que vê a comunicação como uma dádiva do Deus criador aos seres humanos para permitir a vida em comum com a harmonia, a justiça e a paz com toda a Criação. No entanto, homens e mulheres também foram corruptores desse projeto criativo de Deus. A comunicação humanizadora, para a comunhão, é frequentemente substituída por atitudes de competição, ciúme, tensões, inveja, ganância, guerras.

O livro bíblico de Gênesis trata do dom da comunicação de Deus e dessa condição humana. É neste contexto que emerge a narrativa da Torre de Babel: um projeto de construção de uma cidade e uma torre que faria um célebre grupo humano dominar sobre os outros ("para que não sejamos espalhados por toda a terra”, Gênesis 11,4). Um projeto de dominação e concentração de alguns sobre os outros - sem harmonia, sem justiça, sem paz. Uma narrativa da corrupção humana do dom de comunicação de Deus: "em toda a terra havia apenas uma linguagem e um modo de falar". Unidade imposta pelo projeto de dominação e concentração: um único modo de falar - a linguagem do poder de alguns sobre os outros. A ação de Deus sobre os construtores da Torre é uma bênção: comunicação/comunhão não é singularidade ou homogeneidade; comunicação/comunhão é diversidade e diferença. Viver na unidade, na justiça e na paz, é aprender com diversidade e diferença, especialmente em tempos de cultura de convergência no mundo global. 


\section{Ver o que está diante de nós...}

Estamos vivendo uma época de transformações socioculturais e econômicas que dão origem a sentimentos que variam entre euforia e perplexidade. Isso porque vivemos a era da comunicação - um tempo revolucionário caracterizado por conquistas tecnológicas que, há apenas algumas décadas, só eram imagináveis em filmes de ficção.

Transformações na capacidade humana de comunicar possibilitaram mudanças em diferentes aspectos relacionados à vida humana: relacionamentos, atos de informar e buscar informações, educação, entretenimento, consumo. Através dessas mudanças, receptores se tornam protagonistas - papel que até poucas décadas atrás era dos emissores (HALL, 2006).

$\mathrm{Na}$ contemporaneidade, essa característica do receptor é intensificada devido ao desenvolvimento da sociedade da informação e dos processos interativos, ou seja, ações que marcam a recepção são potencializadas com a possibilidade de interatividade. Isso significa que o receptor desenvolve a capacidade de se tornar um emissor e se relacionar mais intimamente com os emissores.

Um dos sentidos fortes desses tempos, portanto, é a participação. Dois elementos sinalizam esse processo sociocultural e econômico: os computadores (e mais particularmente a internet) e os telefones celulares.

A ideia de convergência parece explicar essa dinâmica: a viabilidade em grande escala dessas tecnologias em um único dispositivo para acessar várias redes e serviços (JENKINS, 2008). Em outras palavras, diferentes funções e mecanismos de comunicação envolvidos/ inseridos (convergentes) em uma única máquina, possibilitados pela tecnologia digital. Essa convergência permitiu a expansão da capacidade das mídias: há um encontro entre as mídias analógicas tradicionais e as mídias digitais, produzindo interconexões e gerando novos produtos e meios de obtenção de informações.

Para que a participação se torne eficaz, surgem as ferramentas que facilitam a ação dos usuários-emissores - blogs, podcasts, wikis, fóruns de discussão, mídias sociais. Eles não trabalham para a centralização da informação, não estão necessariamente ligados às empresas de comunicação, não se limitam a enviar apenas informações, não são ligados à publicidade e marketing, não são concessões estatais e não estão limitados às necessidades de cobertura geográfica. Essa cultura de participação que promove mídias convergentes transforma os processos de comunicação com a possibilidade de ampliação do acesso a diferentes ideias e opiniões e recriação de mensagens.

Foi o pesquisador Henry Jenkins que, atento a este contexto contemporâneo, criou o termo "cultura de convergência" para criticar a concentração 
da atenção na "convergência das mídias" e chamar a atenção para o que considera fundamental neste fenômeno, algo que não diz respeito apenas às tecnologias ou transformações industriais, mas que se refere à cultura, ao modo como as sociedades vivem. Jenkins se mostra interessado na dinâmica social a partir dessas novas possibilidades trazidas pelo digital e suas combinações. Por isso, o autor questiona que convergência diga respeito apenas a aparelhos com múltiplas funções e destaca que ela estimula novas conexões midiáticas, já que os usuários se sentem capazes de ir, eles próprios, em busca de informação, e mais: de transmitir a sua própria. Por isso, Jenkins assim define convergência:

fluxo de conteúdos através de múltiplos suportes midiáticos, à cooperação entre múltiplos mercados midiáticos e ao comportamento migratório dos públicos dos meios de comunicação, que vão a quase qualquer parte em busca das experiências de entretenimento que desejam (JENKINS, 2008, p.27).

Essa cultura de participação que a mídia convergente promove, transforma os processos de comunicação com a possibilidade ampliada de acesso a diferentes ideias e opiniões e recriação de mensagens.

Jenkins não despreza o aspecto de marketing que está presente nesta experiência de comunicação, porque todas as informações que são acessadas ou criadas podem ser (e foram) transformadas em produtos de consumo. Essa revolução tem consequências, portanto, para o setor de comunicações e corporações/oligopólios da mídia, que buscam controlar todos os tipos de redes e se promover como convergências. Neste contexto, os antigos monopólios de radiodifusão dão origem a oligopólios que ganham força à medida que a convergência tecnológica permite que as empresas atuem em setores de mercado previamente separados.

\section{Julgar pela Palavra de Deus - a Teologia da Comunicação}

A palavra comunicare tem suas origens no latim, que significa "tornar algo comum”, a ação de tornar ideias (conhecimento, informação, opiniões) e sentimentos comuns. Aqui reside uma dimensão do inter. A partir do momento em que o ser humano torna comuns ideias e sentimentos, o inter surge muito fortemente: o interpessoal, o intergrupo, intimamente relacionado à dimensão do diálogo. O diálogo também se refere ao encontro e aproximação, troca (WOLTON, 2006).

Portanto, aqui vemos elementos que compõem este significado de comunicação. As Ciências Humanas e Sociais nos ensinam que eles fazem parte da condição humana: o ser humano, como ser social, não existe para viver 
sozinho; ele só sobrevive na relação com outros seres. Para existir, homens e mulheres precisam conviver, gozar de companheirismo, comunhão. Então, comunicação é a possibilidade de concretizar tudo isso, incluindo a diversidade que é da natureza da humanidade. Portanto, o ser humano sempre procura maneiras de se comunicar além de si mesmo e de estender a possibilidade de comunhão além das fronteiras geográficas. Consequentemente, surgem as mídias como extensão dos seres humanos (McLUHAN, 1974).

A comunicação humana em todas as suas formas é inerente ao ser humano e à sua necessidade de conviver. Isso é reconhecido nos parágrafos acima. No entanto, a tendência humana de concentrar, em vez de tornar as coisas comuns, e de dominar sobre o Outro Igual, em vez de compartilhar a solidariedade, deve ser levada em conta nesse processo. É por isso que os projetos de participação nas mídias, por meio da cultura da convergência, inconscientemente ou não, revelam a contradição humana.

Quando lançamos um olhar sobre esta dinâmica sob a ótica da fé, podemos basear nosso entendimento na teologia da formação do ser humano na criação do mundo, conforme narrado no livro de Gênesis, capítulos 1 a 4. Uma forte imagem vem do capítulo 2, verso 18: "Não é bom que o homem esteja só". Muitas vezes, este texto é lido nas comunidades de fé cristã nas celebrações de casamento, para falar da união entre um homem e uma mulher, mas aqui é importante destacar que a narrativa se refere a dimensões muito mais profundas.

Quem quer que estude o texto em sua versão hebraica, no texto original, a palavra-chave nessa passagem é Adam: "não é bom que Adam esteja sozinho". Em hebraico, Adam não significa "homem", o ser homem, os humanos do sexo masculino, como as traduções comuns popularizam o termo. Adam significa humanidade, o ser humano no coletivo. Para o humano masculino, há uma palavra hebraica apropriada - ish - como há uma palavra para mulher, para o humano feminino - isha. Essas duas personagens, mulher - isha -, e homem - ish -, são mencionadas na narrativa da criação do mundo. No entanto, neste texto de Gênesis 2,18, Adam se refere à humanidade, aos seres humanos, àqueles que vêm da Adamah, a terra, em hebraico. Adam, o ser humano que emerge da terra, é criado a partir dele, homem e mulher, ambos (RUIZ, 2003).

Fundamentada nesta inspiração teológica, é possível identificar a profunda compreensão presente em Gênesis que se refere ao ser humano e às relações humanas: "não é bom que Adam, o ser humano/a humanidade, esteja só”. No entanto, os tradutores clássicos do texto bíblico optaram pela generalização tradicional (sexista) da linguagem, usando o "homem" masculino para 
tratar o todo, e o texto se torna "não é bom que o homem esteja só". Nesta conotação, um homem que não deveria estar sozinho deveria procurar uma mulher por companhia, o que esconde o rico sentido da narrativa original: Adam como homem e mulher não deveria estar sozinho. A humanidade tem vocação para viver em coletivo; um presente de Deus, o Criador.

Portanto, as noções científicas de Antropologia, Sociologia, Psicologia, Biologia, de que os seres humanos precisam uns dos outros (a condição humana de existir como ser social) e que precisam se comunicar para viver coletivamente, se refletem em Gênesis 2,18: Deus criou o ser humano com a vocação de viver coletivamente, em meio às diferenças entre homens e mulheres, entre diferentes grupos. Além disso, só é possível viver no coletivo através da comunicação humana.

No ato criador de Deus, existe uma condição humana: para existirem, homens e mulheres têm que viver, desfrutar de companhia, comunhão e, por isso e para isso, comunicar com toda a diversidade e isto está no coração da Criação. A raiz "com" está em todas essas palavras e carrega em si mesmo o sentido da coletividade. A comunicação, portanto, é inerente à condição humana e promove o encontro da palavra filosófica, que afirma que o ser humano "é" comunicação, com a palavra teológica.

O ser humano não se comunica, o ser humano não tem comunicação, os humanos são comunicação, porque já nasceram com essa capacidade/dom. Desde que é recém-nascido, embora incapaz de articular o pensamento, o ser humano já se comunica: o bebê chora, manifesta alegria, calma, preocupação, aborrecimento, porque essas expressões já são inerentes à própria condição humana... O ser humano é comunicação.

\section{Da comunhão à competição}

Uma Teologia da Comunicação também deve refletir que o ser humano corrompe esse projeto criador de Deus. O Criador diz: "Não é bom que o ser humano esteja só" - homens e mulheres devem viver bem, em harmonia, em paz, compreenderem-se um aos outros, comunicarem-se, aproximarem-se, aprenderem uns com os outros, mas o ser humano corrompe este plano divino quando decide tomar o lugar de Deus.

De acordo com a narrativa da Criação, a humanidade decidiu comer o fruto da árvore do conhecimento do bem e do mal, propriedade de Deus e vedada aos seres humanos (Gênesis 3). No entanto, decidiu comer a fruta, obter o conhecimento de Deus, ser igual a Deus e corromper o projeto divino. Por causa disso, os humanos passam a não se entender mais: a continuação da narrativa é a história de Caim e Abel, na qual um irmão mata 
o irmão, uma consequência do desejo de possuir o conhecimento de Deus - competição, ciúmes, tensões e muros construídos entre os seres humanos.

O Gênesis trata a condição humana como um ser comunicativo por excelência. A condição humana é ter comunhão, comunicar-se, viver em harmonia, mas, em contradição, do projeto humano vem a corrupção do projeto divino. Abel e Caim passam a estar entre homens e mulheres; dentro do ser humano passa a existir a luta entre comunhão e barreira, aproximação e destruição do outro, companheirismo e competição.

É nesse contexto que o Gênesis traz outra narrativa, a da Torre de Babel. Refere-se a um projeto de construção de uma cidade em um terreno plano e, ali, uma torre que faria um grupo celebrado, buscando ser como Deus (de novo) uma vez que alcançaria, através da torre, os lugares altos da moradia de Deus. O grupo se concentraria naquele mesmo lugar para dominar os outros ("para que não sejamos espalhados sobre a face de toda a terra", Gênesis 11,4). Um projeto de dominação e concentração de um sobre os outros - de uma cidade sobre a outra ou de uma cidade sobre o campo, que era o contexto em que o texto foi produzido (SCHWANTES, 2002).

Torres, historicamente, foram projetos de controle militar, especialmente no tempo da narrativa, sob o domínio do Império Babilônico. Um exemplo de projeto que corrompe o desejo divino de comunhão e harmonia entre a humanidade.

Milton Schwantes (2002) chama a atenção para este texto como uma narrativa da corrupção humana no plano divino. Ele indica que no capítulo 11, verso 1, há um exemplo disto: "E toda a terra era de uma só língua e um só discurso". Representa uma unidade imposta pelo projeto de dominação e concentração: um único modo de falar - o poder da linguagem de uns sobre os outros.

É por isso que Deus, o Criador, aparece no texto para reconhecer isso (Gênesis 11,6): "Eis que o povo é um e todos têm uma só língua; e isto é o que começam a fazer; agora não haverá restrição para tudo o que eles intentarem fazer". O texto diz que Deus desce para ver a cidade e a torre (afinal, Deus está muito acima desses projetos humanos...) e decide falar, também no plural (Gênesis 11,7): "Vamos descer, e lá confundir sua linguagem, para que eles não entendam um a língua do outro". E o texto continua dizendo (Gênesis 11,8-9): "Assim o Senhor os espalhou dali sobre a face de toda a terra; e cessaram de edificar a cidade. Por isso se chamou o seu nome Babel...”. Babel, Babilônia: o nome do dominador, o opressor, que, no contexto do Gênesis, Deus dispersa e de quem Deus confundiu a única língua de concentração e dominação, para garantir a diversidade. É na diversidade 
que o projeto de Deus é implementado e não na linguagem única dos seres humanos que buscam alcançar a altura de Deus. Portanto, a diversidade de línguas pode ser vista não como uma maldição, mas como a ação de Deus por justiça e paz na vida coletiva, entre a humanidade.

\section{Onde estão as divergências?}

Estas bases teológicas contribuem para o discernimento e para ações frente à realidade da cultura de convergência. Como já mencionado, é inegável que a convergência e suas consequências são o resultado da busca humana pela capacidade de se comunicar e possibilitar o "inter", o comum. Tudo resultante do dom dado por Deus ao ser humano, com vistas ao seu projeto humanizante, de comunhão, encontro, solidariedade.

No entanto, não devemos esquecer que os seres humanos têm a tendência de corromper o projeto divino e implementar seus próprios projetos de se tornarem como Deus e se concentrarem e dominarem os outros, em vez de estarem uns com os outros, em solidariedade. É por isso que os projetos de participação nas mídias, que passam pela cultura da convergência, inconscientemente ou não, revelam essas contradições humanas.

As pessoas comunicam fortemente através das mídias convergentes a banalização do lazer e do entretenimento, a exclusão social e cultural, a incitação à violência simbólica e moral, a prática do abuso sexual, o consumismo. É fato que as pessoas ganham mais acesso e interação com informações e entretenimento. No entanto, em grande parte, o conteúdo tem sido composto de abordagens de baixo nível a valores socioculturais (incentivo à trapaça, competição, desprezo pelos outros e vulgarização da vida); livre expressão de racismo, sexismo, discriminação de pessoas com deficiência e de pessoas que vivem em áreas periféricas (geralmente aquelas com menos acesso a veículos convergentes); agressão moral (o chamado cyberbullying); de pedofilia; de pornografia; apelo exacerbado ao consumo; de submissão de culturas consideradas inferiores que carecem de espaço para maior expressão.

Dominique Wolton alerta:

Quanto mais as mensagens se globalizam, mais as diferenças culturais da comunicação se afirmam. O risco é, evidentemente, a defasagem crescente entre, de um lado a dimensão técnica e econômica da comunicação, e, de outro, a dimensão social e cultural. Seis bilhões e meio de computadores não bastariam de modo algum para assegurar mais comunicação entre os homens. Quanto mais fáceis se tornam as trocas do ponto de vista técnico, mais se torna essencial e difícil satisfazer as condições culturais e sociais para que a comunicação seja algo diferente de uma transmissão de informação. Foi o que chamei, referindo-me à Internet, de "risco das solidões interativas". Em outras palavras, quanto mais mensagens estiverem em circulação, mais nos confrontamos com 
dois problemas. Aquele das condições a satisfazer para um mínimo de comunicação autêntica. E aquele do respeito, que vai além da técnica e da economia, à diversidade cultural (WOLTON, 2006, p. 17-18).

Além disso, do ponto de vista do mercado e da indústria das comunicações, marcado por conglomerados, oligopólios, a convergência é concentração: foco/convergência para dominar. Neste caso, há a negação da diferença/diversidade como um valor na existência humana; uma negação da possibilidade do diferente. O poder que destaca a indústria das comunicações reflete o poder imperial político-econômico-cultural estabelecido no mundo. De quais países são as empresas que controlam o mercado de comunicação? Qual idioma prevalece nessas tecnologias e suas ferramentas? (GOIS, 2008)

Outra semelhança com Babel: concentração de poder e dominação e "todos falando a mesma língua" para fazer parte do sistema. Essa é a Babel vivida na contemporaneidade da convergência que promove a negação da diversidade cultural, começando com a única língua do mercado global, o inglês, seguido do que prevalece nas artes, nas notícias, nos conteúdos educacionais, nos valores que se referem ao individualismo, ao consumismo e à concorrência.

Ontem não conseguíamos comunicar por falta de técnicas apropriadas. Hoje, elas pululam, mas não nos compreendemos melhor (...) Hoje em dia, todo mundo vê tudo ou quase tudo, mas percebe, ao mesmo tempo, que não compreende melhor o que acontece. A visibilidade do mundo não basta para torná-lo mais compreensível. Mesmo onipresente, a informação não pode explicar um mundo percebido como mais complexo, mais perigoso, menos controlável e em que as diferenças culturais e religiosas se exacerbam. O fim das distâncias físicas revela a incrível extensão das distâncias culturais (WOLTON, 2006, p. 19).

Além disso, a competição de mercado pelo controle da mídia convergente e pela extração de mais incentivos ao consumismo traz a questão da privacidade. Se, por um lado, a interação entre os usuários é positiva, trocar informações, imagens e dados, por outro, as atitudes das empresas são preocupantes. Eles montam bancos de dados com base nos hábitos de navegação e nas informações que o usuário fornece na rede. Pessoas nem sempre percebem a dimensão de quanto estão se expondo (LEMOS, 2007).

\section{Agir em nome do projeto divino: o desafio da fé em dimensão pública}

Esta é uma realidade em mudança, uma dinâmica, cujos movimentos devem ser monitorados de perto com todas as suas nuances. Importa aqui recuperar o desafio do pesquisador Douglas Kellner, que, ao estudar as mí- 
dias tradicionais, se refere a elementos relevantes para a realidade das mídias convergentes:

mídia e a cultura podem ser transformadas em instrumentos de mudança social. Para tanto, é preciso dar mais atenção à mídia alternativa do que se fez até agora, refletindo-se mais no modo como a tecnologia da mídia pode ser reconfigurada e usada em favor das pessoas. Essa tarefa implica o desenvolvimento de um ativismo capaz de intervir na televisão de acesso público, na rádio comunitária, nos meios de comunicação por computador e em outros domínios que hoje estão surgindo. Para obterem uma participação genuína, as pessoas precisam adquirir conhecimentos sobre a produção da mídia e sobre a criação de produtos divulgáveis. A intensificação do ativismo na mídia poderia ampliar significativamente a democracia, com a proliferação de novas ideias e com a possibilidade de manifestação das opiniões até agora silenciadas ou marginalizadas (KELLNER, 2001, p. 426).

Essa reflexão leva à questão das relações humanas e do desafio da comunicação. Pessoas capazes de informar, transmitir e se expressar, transformadas em receptores ativos, usuários interativos da mídia, não representam elementos suficientes para realizar a comunicação que promove interação e comunhão. Como observado acima, a comunicação é encontro, comunhão, verbal e não-verbal, interpessoal ou social; para ser plenamente alcançada, não pode limitar-se à transmissão de ideias, mas implica o Outro Igual e uma relação autêntica com ele/ela.

O encontro pode ocorrer no silêncio; ao passo que inversamente, o jovem que anda na rua multiconectado poderá se revelar incapaz de dizer "bom dia" ou "obrigado" a quem cruzar com ele. Do mesmo modo, um adulto "livre" e "moderno" poderá ser incapaz de ouvir as palavras de indivíduos que não compartilham suas opiniões... (WOLTON, 2006, p. 31).

Assumir, portanto, a fé em dimensão pública significa avocar uma compreensão de comunicação que seja plena, abrangente, ecumênica, e que vise à inserção cristã nos espaços públicos plurais, o que implica participação de cada cristão/cristã como cidadão (CASTRO, 2000). Isto quer dizer assumir o lugar social da Igreja, que não pode ser um corpo isolado, um espaço privado a mais, e deve estar centrada nos três elementos que sinalizam a presença do Reino de Deus no mundo: o kerygma, a diakonia e a koinonia (CUNHA, 2006). E sinalizar o Reino de Deus é a maior tarefa cristã no espaço público.

Anunciar os valores do Reino e sua justiça (que caminham na contramão de todo individualismo, consumismo e exclusão), trabalhar em todas as frentes para que a dignidade humana seja realidade (tendo como alvo a inclusão das pessoas em todas as dimensões da vida pública) e viver e promover a 
comunhão entre as pessoas e comunidades (desprezando toda a forma de exclusão e discriminação de pessoas e grupos) são as formas de expressão da fé pública e participação missionária.

Crescimento numérico, presença nas mídias, representação parlamentar, hoje projetos tão caros a grupos cristãos na América Latina, como formas de expressão no espaço público. Elas não estão descartadas, e podem ser consequência da busca de uma atuação pública, mas não devem ser condição ou finalidade para uma presença pública dos cristãos/cristãs.

Por isso, ao se relacionar comunicação e fé pública se faz emergir o desafio pastoral de trabalhar na formação de cristãos/cristãs humanizados, que consigam desenvolver relacionamentos mais densos; que busquem aquisição de conhecimento que valorize a diferença; que reconheçam a diversidade como componente da vida em sociedade; que sejam interativos e produzam narrativas críticas e respeitosas, que não sejam meras repetições do que é recebido.

Isso significa o desenvolvimento de formas de comunicação nas comunidades e na esfera global que trabalhem pela desconcentração de processos políticos, econômicos e culturais de dominação; que facilitem o uso pleno das mídias disponíveis para todas as pessoas em todos os lugares, com preços justos e razoáveis no custo de equipamentos e tarifas.

Comunicar nesse sentido pleno é trabalhar pelo projeto de Deus para a sua criação, na qual Adam não deve viver só, mas em encontro, comunhão, harmonia, solidariedade, sem falar uma língua única nem concentrar poder em um só grupo e lugar, pelo contrário, experimentando a diversidade e com ela aprendendo.

\section{Referências bibliográficas}

CASTRO, Clovis Pinto de. Por uma fé cidadã: A dimensão pública da Igreja. Fundamentos de uma pastoral da Cidadania. São Paulo/São Bernardo do Campo: Loyola/UMESP, 2000.

CUNHA, Magali do Nascimento. Missão e compromisso ecumênico. Reflexões a partir do contexto pastoral latino-americano no século XXI. Caminhando, São Bernardo do Campo, v. 17, n. 1, p. 80-87, 2006.

GOIS, Miguel Ventura Santos. A influência dos estrangeirismos na língua portuguesa: um processo de globalização, ideologia e comunicação. Philologus, ano 14, n. 40, p. 14-34, jan./ abr.2008. Disponível em: http://www.filologia.org.br/rph/ANO14/40/ RPH40.pdf. Acesso em 17 dez 2018.

JENKINS, Henry. Cultura da Convergência. São Paulo: Aleph, 2008.

KELLNER, Douglas. A cultura da mídia: estudos culturais: identidade e política entre o moderno e o pós-moderno. Bauru, SP: EDUSC, 2001.

HALL, Stewart. Codificação/Decodificação. In: HALL. Da diáspora: identidades e mediações culturais. Belo Horizonte: Editora da UFMG, 2006, p. 365-384. 
LEMOS, André. Cidade e mobilidade. Telefones celulares, funções pós-massivas e territórios informacionais. Matrizes, n. 1, p. 121-137, out. 2007.

MCLUHAN, Marshall. Os meios de comunicação como extensões do homem. São Paulo: Cultrix, 1974.

RUIZ, Castor Bartolomé. Os paradoxos do imaginário. São Leopoldo: Unisinos, 2003.

SCHWANTES, Milton. Projetos de esperança: meditações sobre Gênesis 1-11. São Paulo: Paulinas, 2002.

WOLTON, Dominique. É preciso salvar a comunicação. São Paulo: Paulus, 2006.

Submetido em: 20-9-2018

Aceito em: 19-12-2018 